an oriP replicon is dependent upon an infrequent, epigenetic event. Mol. Cell. Biol. 21:4149-4161.

3. Ciufo, D.M., et al. 2001. Spindle cell conversion by Kaposi's sarcoma-associated Herpesvirus: Formation of colonies and plaques with mixed lytic and latent gene expression in infected primary dermal microvascular endothelial cell cultures J. Virol. 75:5614-5626.

4. Bais, C., et al. 2003. Kaposi's sarcoma associated herpesvirus G protein-coupled receptor immortalizes human endothelial cells by activation of the VEGF receptor-2/KDR. Cancer
Cell. 3:131-143.

5. Montaner, S., et al. 2003. Endothelial infection with KSHV genes in vivo reveals that vGPCR initiates Kaposi's sarcomagenesis and can promote the tumorigenic potential of viral latent genes. Cancer Cell. 3:23-36.

\section{East meets West: an herbal tea finds a receptor}

\author{
Mitchell A. Lazar
}

Division of Endocrinology, Diabetes, and Metabolism, Departments of Medicine and Genetics, and the Penn Diabetes Center, University of Pennsylvania School of Medicine, Philadelphia, Pennsylvania, USA

Jaundice, which is caused by accumulation of bilirubin, is extremely common in newborn infants. Phototherapy is an effective treatment, but a drug therapy would also be desirable. A Chinese herbal remedy for jaundice called Yin Zhi Huang is now shown to activate a liver receptor that enhances the clearance of bilirubin (see the related article beginning on page 137). This discovery could lead to improved pharmaceutical treatments for neonatal jaundice.

J. Clin. Invest. 113:23-25 (2004). doi:10.1172/JCI200420661.
Advances in Western medicine have dramatically increased health and life expectancy (1). Nevertheless, over $\$ 4$ billion is spent per year on herbal remedies that are complementary or alternative to Western-style care (2). Prescription medicines are usually purified molecules whose biological target is established and whose efficacy is endorsed by regulatory agencies. By contrast, herbal medicines often contain many ingredients whose effects on biochemical pathways are unknown and whose efficacy is unproven in controlled studies. A report in the current issue of the JCI helps to bridge this gap. David Moore and colleagues (3) show the improvement of jaundice by a Chinese herbal tea called Yin Zhi Huang (YZH), "boiled down” to one component that regulates the activity of a nuclear receptor previously implicated in bilirubin clearance $(4,5)$. This discovery provides a mechanistic ration-

\footnotetext{
Address correspondence to: Mitchell A. Lazar, University of Pennsylvania School of Medicine, 611 Clinical Research Building, 415 Curie Boulevard, Philadelphia, Pennsylvania 19104-6149, USA. Phone: (215) 898-0198; Fax: (215) 898-5408;

E-mail: lazar@mail.med.upenn.edu.

Conflict of interest: The author has declared that no conflict of interest exists.

Nonstandard abbreviations used: Yin Zhi Huang (YZH); constitutive androstane receptor (CAR).
}

ale for pursuing an ingredient in $\mathrm{YZH}$ as a lead to improve upon the standard Western treatment for fetal jaundice.

\section{While there's tea, there's hope. -Sir Arthur Pinero}

Herbal remedies are often produced in the form of tea, that is, a decoction of dried plant leaves in boiling water. In today's Western world, teas serve as beverages for enjoyment as well as for herbal therapies. The former use has widespread acceptance, whereas the therapeutic use of tea is not espoused by mainstream Western medicine, largely because Western pharmacology has focused on purified chemical compounds, with defined mechanisms of action, whose effectiveness has been proven in controlled studies. By contrast, most teas used for medicinal purposes are admixtures of phytochemicals whose efficacy and biological target(s) are unproven by Western standards. This can threaten relationships between physicians guided by the Western medical literature and millions of their patients who opt to use teas preventively or therapeutically for cancer, inflammatory disease, and metabolic disease (6). At the same time, Eastern remedies may contain critical clues for disorders that have been refractory to Western medicine.

\section{Table 1}

Components of herbal remedies that target nuclear receptors

\begin{tabular}{|c|c|c|c|c|}
\hline Therapy & Indication & Compound & Receptor & Reference \\
\hline Rhei rhizoma ${ }^{\mathrm{A}}$ & Prostate cancer & Lindleyin & ER & 17 \\
\hline Ginseng & Stress & Ginsenoside-Rg1 & ER & 18 \\
\hline Grapeseed/red wine & Cardiovascular & Resveratrol & ER & 9 \\
\hline Scutellaria baicalensis ${ }^{\mathrm{B}}$ & Prostate cancer & Baicalein & AR & 19 \\
\hline Dioscorea villosa ${ }^{C}$ & Menopause & Diosgenin & PR & 20 \\
\hline Longmu Zhuanggu Chongji & Rickets & Vitamin D2 & VDR & 21 \\
\hline Xiao Chai Hu Tang & Leukemia & Retinoic acid & RAR & 22 \\
\hline Guggul tree resin & Lipid disorder & Guggulsterone & FXR & 23 \\
\hline Pseudolarix kaempferi & Fungal infection & Pseudolaric acid B & PPAR $\alpha$ & 24 \\
\hline Hypericum perforatum ${ }^{\mathrm{D}}$ & Depression ${ }^{\mathrm{E}}$ & Hyperforin & PXR & 25 \\
\hline Artemisia capillaris ${ }^{\mathrm{F}}$ & Jaundice & Dimethylesculetin & CAR & 15 \\
\hline Soy & Menopause & Genistein & $E R, A R, P R$ & 26 \\
\hline Labiatae $^{\mathrm{G}}$ & Lipid disorders & Isoprenoids & $\operatorname{PPAR} \alpha / \gamma$ & 27 \\
\hline
\end{tabular}

All examples are from traditional Chinese medicine except Guggul gum (Indian Ayurvedic), Dioscorea villosa (Mexican), and red wine. Note that not all examples could be listed, due to space constraints. Although several illustrative estrogen receptor compounds are shown, there are many environmental estrogens, which are reviewed elsewhere (27). ARhubarb. ${ }^{B}$ One of eight Chinese herbs in the herbal mixture PC-SPES (whose name is derived from PC, prostate cancer, and Latin spes, meaning "hope"): Isatis indigotica; Glycyrrhiza glabra and Glycyrrhiza uralensis (licorice); Panax pseudo-ginseng (ginseng); Ganoderma lucidum; Scutellaria baicalensis (skull cap); Dendranthema morifolium Tzvel (chrysanthemum); Rabdosia rubescens; and Serenoa repens (saw palmetto). 'Yam. DSt. John's wort. ENuclear receptor likely involved in toxicity rather than antidepression. FWormwood (component of Yin Zhi Huang and Yin Chin). GHerb family including basil, rosemary, oregano, and sage. ER, estrogen receptor; AR, androgen receptor; PR, progesterone receptor; VDR, vitamin D receptor; $R A R$, retinoic acid receptor; FXR, farnesyl X receptor (bile acid receptor); PXR, pregnane $X$ receptor; CAR, constitutive androstane receptor. 


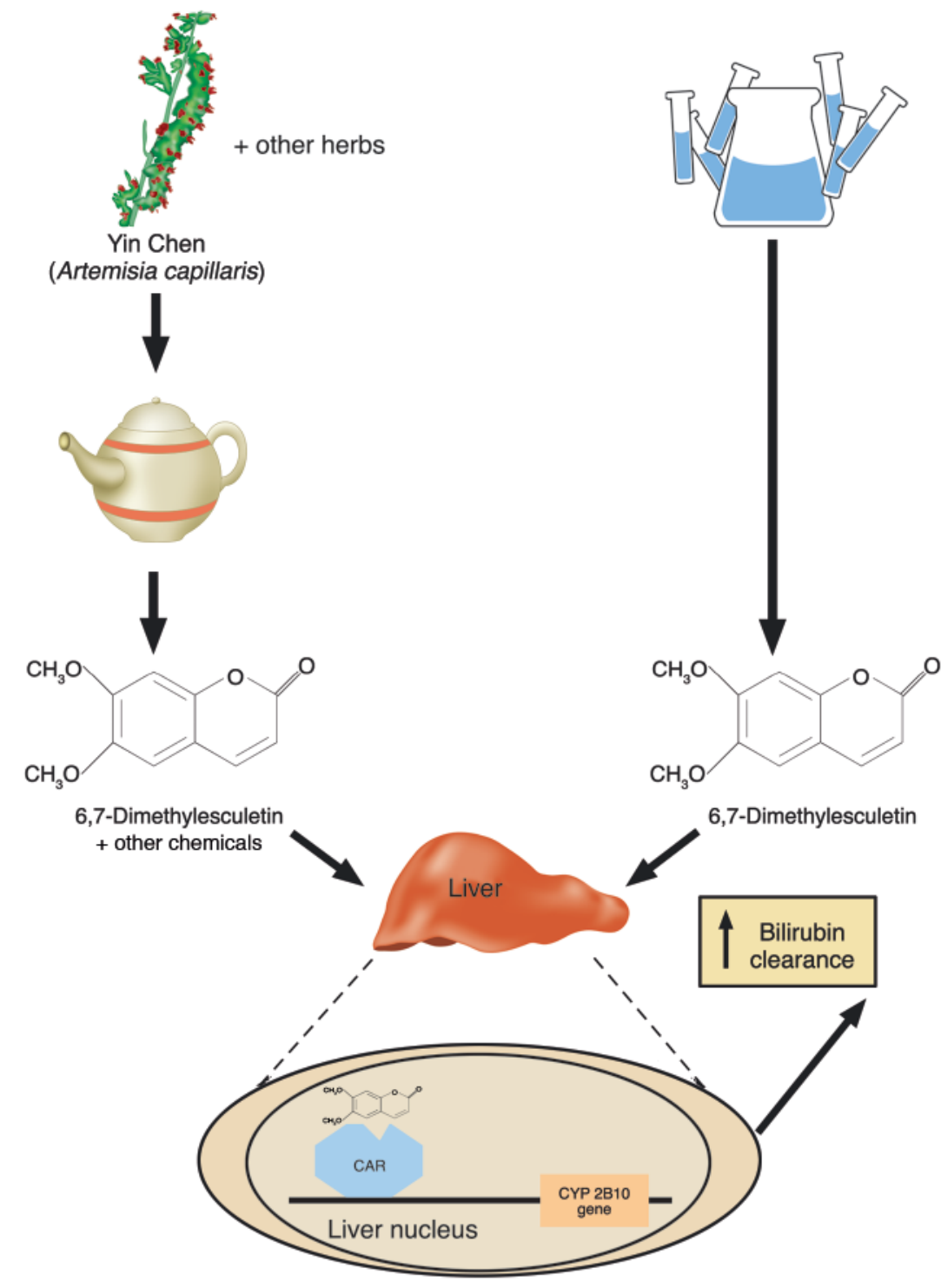

Figure 1

Eastern and Western paths to medicine. 6,7-Dimethylesculetin, in a wormwood tea or as a purified chemical, binds to and activates the hepatic nuclear receptor CAR and its target genes including CYP 2B10, leading to increased bilirubin clearance. Brewing of wormwood yields a tea that contains other chemicals, with potential for additional benefit or toxicity, or both.

\section{Nuclear receptors as targets of herbal remedies}

Holistic medicine holds that herbal remedies work better when the whole complex of plant phytochemicals is kept together than when these chemicals are purified and administered singly or in combination. This hypothesis is difficult to put to stringent experimental test and remains a divisive point between Eastern and Western approaches. On the other hand, investigation of herbal remedies has revealed individual components that target nearly all classes of signaling molecules.
There are 48 nuclear receptors, some of which are "orphans," meaning that no endogenous ligand has yet been found (9). At least ten of these receptors have been shown to be directly activated by compounds purified from herbal remedies (Table 1). Some compounds have a complex pharmacology; for example, grapeseed-derived resveratrol is an estrogen receptor ligand (10) but has also been suggested to activate a histone deacetylase enzyme implicated in the biology of aging (11). Other phytochemicals target multiple nuclear receptors (see Table 1 for examples). The pharmaceutical industry is now exploiting similar, less specific compounds, such as antidiabetic drugs that activate both PPAR $\alpha$ and PPAR $\gamma$ (12). Indeed, although purified hormones have mostly replaced glandular extracts in Western medicine (13), a natural extract of pregnant mare's urine containing at least ten estrogenic compounds is a widely prescribed treatment for menopausal symptoms (14).

\section{When things are investigated, then true knowledge is achieved. -Confucius}

Neonatal jaundice is extremely common and may lead to neurotoxicity (15). The treatment of choice for this condition in Western medicine is ultraviolet light therapy; pharmaceutical treatments have not been popular. Two groups have recently noted that the nuclear receptor constitutive androstane receptor (CAR) enhances bilirubin clearance $(3,4)$. In the present issue of the JCI, noting that Chinese medicine uses YZH and a tea called Yin Chin for the treatment of jaundice, Huang et al. test the hypothesis that the Chinese remedies exert their effects via this mechanism (3). $\mathrm{YZH}$ and Yin Chin were obtained not from a chemical supplier but from a Chinese-herb store, were prepared as teas, and then were administered to mice (Figure 1). The herbal teas accelerated the clearance of bilirubin in normal mice, but not in mice that had been genetically engineered to lack CAR, demonstrating a critical role for this nuclear receptor. But that is only half of the story - the teas contain many ingredients, including one component (Scutellaria) that has been 
shown to contain an androgen receptor ligand (Table 1). However, the systematic study by Huang et al. reveals that a single compound found in both YZH and Yin Chin (6,7-dimethylesculetin) is sufficient to activate CAR and induce bilirubin clearance. This is a wonderful example of knowledge gained by applying the Western scientific method to an Eastern herbal remedy. It will be very exciting if a pure compound emerges from the tea leaves as a pharmacological therapy for neonatal jaundice that is complementary or alternative to the current Western practice of phototherapy (16).

1. Kinsella, K., and Gist, Y.J. 1998. Gender and Aging: Mortality and Health. U.S. Department of Commerce, U.S. Bureau of the Census. Washington, D.C. $1 \mathrm{~B} / 98-2$.

2. Carey, J. 2003. Herbal remedies: a \$4 billion enigma. BusinessWeek online, 28 April. http:// www.businessweek.com/magazine/content/ 03_17/b3830095_mz025.htm.

3. Huang, W., Zhang, J., and Moore, D.D. 2004. A traditional herbal medicine enhances bilirubin clearance by activating the nuclear receptor CAR. J. Clin. Invest. 113:137-143. doi:10.1172/JCI200418385.

4. Huang, W., et al. 2003. Induction of bilirubin clearance by the constitutive androstane receptor (CAR). Proc. Natl. Acad. Sci. U. S. A. 100:4156-4161.

5. Xie, W., et al. 2003. Control of steroid, heme, and carcinogen metabolism by nuclear pregnane $\mathrm{X}$ receptor and constitutive androstane receptor. Proc. Natl. Acad. Sci. U. S. A. 100:4150-4155.
6. Eisenberg, D.M. 1997. Advising patients who seek alternative medical therapies. Ann. Intern. Med. 127:61-69.

7. Chawla, A., Repa, J.J., Evans, R.M., and Mangelsdorf, D.J. 2001. Nuclear receptors and lipid physiology: opening the X-files. Science. 294:1866-1870.

8. Lazar, M.A. 2003. Mechanism of action of hormones that act on nuclear receptors. In William textbook of endocrinology. P.R. Larsen, H.M. Kronenberg, S. Melmed, and K.S. Polonsky, editors. W.B Saunders Co. Philadelphia, Pennsylvania, USA. 35-44.

9. Willson, T.M., and Moore, J.T. 2002. Genomics versus orphan nuclear receptors: a half-time report Mol. Endocrinol. 16:1135-1144.

10. Klinge, C.M., et al. 2003. Estrogenic activity in white and red wine extracts. J. Agric. Food Chem. 51:1850-1857.

11. Howitz, K.T., et al. 2003. Small molecule activators of sirtuins extend Saccharomyces cerevisiae lifespan. Nature. 425:191-196.

12. Etgen, G.J., et al. 2002. A tailored therapy for the metabolic syndrome: the dual peroxisome proliferator-activated receptor-alpha/gamma agonist LY465608 ameliorates insulin resistance and diabetic hyperglycemia while improving cardiovascular risk factors in preclinical models. Diabetes. 51:1083-1087.

13. Schwartz, T.B. 1999. Henry Harrower and the turbulent beginnings of endocrinology. Ann. Intern Med. 131:702-706.

14. Bhavnani, B.R. 2003. Estrogens and menopause: pharmacology of conjugated equine estrogens and their potential role in the prevention of neurodegenerative diseases such as Alzheimer's. J. Steroid Biochem. Mol. Biol. 85:473-482.

15. Stevenson, D.K., Wong, R.J., Hintz, S.R., and Vreman, H.J. 2002. The jaundiced newborn. Understanding and managing transitional hyperbilirubinemia. Minerva Pediatr. 54:373-382.

16. Dennery, P.A., Seidman, D.S., and Stevenson, D.K 2001. Neonatal hyperbilirubinemia. N. Engl. J. Med. 344:581-590.
17. Usui, T., et al. 2002. The phytochemical lindleyin, isolated from Rhei rhizoma, mediates hormonal effects through estrogen receptors. J. Endocrinol. 175:289-296.

18. Chan, R.Y., Chen, W.F., Dong, A., Guo, D., and Wong, M.S. 2002. Estrogen-like activity of ginsenoside Rg1 derived from Panax notoginseng. J. Clin. Endocrinol. Metab. 87:3691-3695.

19. Hsieh, T.C., Lu, X., Chea, J., and Wu, J.M. 2002. Prevention and management of prostate cancer using PC-SPES: a scientific perspective. J. Nutr. 132(Suppl.):3513S-3517S.

20. Zava, D.T., Dollbaum, C.M., and Blen, M. 1998 Estrogen and progestin bioactivity of foods, herbs, and spices. Proc. Soc. Exp. Biol. Med. 217:369-378.

21. Zhang, L.N., et al. 2000. Determination of vitamin D2 included with beta-cyclodextrin complex in "longmu zhuanggu chongji" by HPLC. Se Pu. 18:52-54.

22. Huang, M.E., et al. 1988. Use of all-trans retinoic acid in the treatment of acute promyelocytic leukemia. Blood. 72:567-572.

23. Urizar, N.L., et al. 2002. A natural product that lowers cholesterol as an antagonist ligand for FXR. Science. 296:1703-1706.

24. Jardat, M.S., Noonan, D.J., Wu, B., Avery, M.A., and Feller, D.R. 2002. Pseudolaric acid analogs as a new class of peroxisome proliferator-activated receptor agonists. Planta Med. 68:667-671.

25. Moore, L.B., et al. 2000. St. John's wort induces hepatic drug metabolism through activation of the pregnane X receptor. Proc. Natl. Acad. Sci. U. S. A 97:7500-7502.

26. Beck, V., Unterrieder, E., Krenn, L., Kubelka, W., and Jungbauer, A. 2003. Comparison of hormonal activity (estrogen, androgen and progestin) of standardized plant extracts for large scale use in hormone replacement therapy. J. Steroid Biochem. Mol. Biol. 84:259-268.

27. Takahashi, N., et al. 2002. Dual action of isoprenols from herbal medicines on both PPARgamma and PPARalpha in 3T3-L1 adipocytes and HepG2 hepatocytes. FEBS Lett. 514:315-322.

\section{The relative roles of growth hormone and IGF-1 in controlling insulin sensitivity}

\section{David R. Clemmons}

Department of Medicine, School of Medicine, University of North Carolina, Chapel Hill, North Carolina, USA

IGF-1 and growth hormone (GH) interact with insulin to modulate its control of carbohydrate metabolism. A new study (see the related article beginning on page 96) shows that blocking the effect of GH in the presence of low serum IGF-1 concentrations enhances insulin sensitivity.

J. Clin. Invest. 113:25-27 (2004). doi:10.1172/JCI200420660.

\footnotetext{
Address correspondence to: David R. Clemmons, Division of Endocrinology, Department of Medicine, University of North Carolina School of Medicine, CB 7170, Chapel Hill, North Carolina 27599, USA. Phone: (919) 966-4735;

Fax: (919) 966-6025;

E-mail: endo@medicineexch.med.unc.edu.

Conflict of interest: The author has declared that no conflict of interest exists.

Nonstandard abbreviations used: growth hormone $(\mathrm{GH})$.
}

Understanding the relative roles of peptide hormones in modulating responsiveness to insulin presents a major challenge because of the adaptability of the growth hormone/IGF-1/ insulin system. Changes in glucose and insulin secretion result in counter-regulatory responses, and modifications in growth hormone $(\mathrm{GH})$ and IGF-1 function alter insulin's ability to maintain normal carbohydrate homeostasis. Historically, this problem has been analyzed in both human and rodent hormone-deficiency models (e.g., GH deficiency) in which the hormone of interest is replaced and the metabolic consequences are determined (1). The recent development of tissue-selective knockout animal models has brought new insights to our understanding of the relative roles of these hormones in carbohydrate homeostasis. In this issue of the JCI, Yakar et al. address the relative roles of $\mathrm{GH}$ and IGF-1 in regulating insulin sensitivity in mice (2). The authors created an animal model in which IGF-1 synthesis in the liver is eliminated and then crossed these animals with mice that overexpress a mutant form of $\mathrm{GH}$ that prevents $\mathrm{GH}$ activation of its receptor. The authors conclude that $\mathrm{GH}$ is a major determinant of insulin resistance in these IGF-1-deficient animals, since, in the presence of low concentrations of serum IGF-1, blocking 